Research Article

Open Access

\title{
Comparative study of Nasogastric Feeding and Nasojejunal Feeding routes of Enteral Nutrition in Acute Pancreatitis
}

\author{
Vinay $\mathbf{G}^{{ }^{\star}}$, Balasubrahmanya $\mathrm{KS}^{1}$ and Dharmendra $\mathrm{BL}^{2}$ \\ IDepartment of General Surgery, Mysore Medical College and Research Institute, Mysore, Karnataka, India \\ ${ }^{2}$ Department of Surgical Gastroenterology, Mysore Medical College and Research Institute, Mysore, Karnataka, India
}

\section{Article Info \\ *Corresponding author: \\ Vinay G \\ Department of General Surgery \\ Mysore Medical College and Research \\ Institute \\ Mysore, Karnataka, \\ India \\ Tel: +91 9986929929 \\ E-mail: dr.vinay1990@gmail.com}

Received: February 06, 2018

Accepted: February 14, 2018

Published: February 20, 2018

Citation: Vinay G, Balasubrahmanya KS, Dharmendra BL. Comparative study of Nasogastric Feeding and Nasojejunal Feeding routes of Enteral Nutrition in Acute Pancreatitis. Madridge J Surg. 2018; 1(1): 19-23.

doi: 10.18689/mjs-1000105

Copyright: @ 2018 The Author(s). This work is licensed under a Creative Commons Attribution 4.0 International License, which permits unrestricted use, distribution, and reproduction in any medium, provided the original work is properly cited.

Published by Madridge Publishers

\begin{abstract}
Background: Nutritional support is an important aspect in the management of acute pancreatits. Upto the mid 1990's, total parenteral nutrition had been comprehensively recommended in the acute phase of pancreatitis. Presently enteral nutrition has replaced parenteral nutrition.
\end{abstract}

Aims and Objectives: The aim of our study is to compare nasogastric feeding and nasojejunal feeding routes of enteral nutrition in acute pancreatitis.

Materials and Methods: A prospective, open label, hospital based, single centered study was conducted among 60 subjects attending General Surgery OPD, K.R. Hospital attached to Mysore Medical College And Research Institute, Mysore meeting the inclusion and exclusion criteria over a period of 24 months from January 2016 to December 2017. All diagnosed cases of acute pancreatitis were included in the study. Exclusion criteria were a delay between onset of symptoms and presentation to hospital of over 4 weeks and a patient who is already on oral feeds at presentation with an acute exacerbation of chronic pancreatitis and patient in shock at presentation. Descriptive statistics, Student t-test, Chisquare test or Fischer Exact test were used to analyse the results.

Results: The mean age group of the study subjects was 36.34 (range 22-64) years. The gender distribution showed 30(100\%) males in nasogastric group 28(93.33\%) males and $2(6.67 \%)$ females in nasojejunal group. Duration of hospital stay was statistically lesser in nasojejunal group as compared to nasogastric group $(p=0.05) .9(30 \%)$ patients in the nasogastric group and $3(10 \%)$ patients in nasojejunal group required to stay in the ICU. 2(6.67\%) patients in nasogastric group and 1(3.33\%) in the nasojejunal group required surgical intervention in the form of necrosectomy.

Conclusion: The nasojejunal route of enteral nutrition appears to be simple safe well tolerated easy to establish and effective route of enteral nutrition in predicting severe acute pancreatitis.

Keywords: Enteral nutrition; Nasogastric feeding; Nasojejunal feeding; Acute pancreatitis.

\section{Introduction}

The incidence of acute pancreatitis has been increasing over recent years [1]. Mild acute pancreatitis may be self-limiting and not require any treatment, but up to $25 \%$ of patients suffer a severe attack and between 30 and $50 \%$ of these will die [2].

About $50 \%$ of deaths occur within the first week; these patients suffer a severe initial attack and develop an exaggerated systemic inflammatory response syndrome with the 
development of multiple organ dysfunction syndrome and death. Patients with a severe attack who survive beyond this period often going to develop extensive retroperitoneal pancreatic necrosis. Infection in necrotic tissue leads to sepsis, a persisting systemic inflammatory response and multiple organ dysfunction syndrome, and accounts for patients who die late [3].

Over decades, the management of acute pancreatitis has been biased by unproven paradigms, which were generated by theories on the pathophysiology of acute pancreatitis. These paradigms have been increasingly questioned over the past two decades, resulting in treatment changes that were again based on personal experience and opinions of experts rather than convincing scientific evaluations. As a result, the overall treatment of acute pancreatitis still differs from center to center, and many physicians declare their management the standard of care [4].

Acute pancreatitis has been traditionally managed with initial fasting on purpose [5]. Nutritional support is an important aspect in the management of acute pancreatits. Upto the mid 1990 's, total parenteral nutrition had been comprehensively recommended in the acute phase of pancreatitis [6]. Presently enteral nutrition has replaced parenteral nutrition [7]. Enteral nutrition is effective, maintains the intestinal mucosal integrity and reduces infectious and other complications, such as multiple organ deficiency syndromes $[8,9]$.

Nasojejunal is the established route of enteral nutrition. Jejunal feeding does not stimulate pancreatic exocrine secretion [10]. Nasogastric enteral nutrition has been recently considered in the management of acute pancreatitis, especially Severe Acute Pancreatitis. The Nasogastric route is simple, easy to establish and cost effective. However, this is potentially against to the requirement of pancreatic rest in the acute inflammation phase [11].

Studies indicate nasojejunal nutrition to be effective and safe $[12,13]$. Before recommendation of nasojejunal enteral nutrition to clinical practice, further randomized controlled trials are needed [14].

The objective of our study was to compare nasogastric and nasojejunal feeding routes of enteral nutrition in acute pancreatitis.

\section{Materials and Methods}

A prospective, open label, hospital based, single centered study was conducted among 60 subjects attending General Surgery OPD, K.R. Hospital attached to Mysore Medical College And Research Institute, Mysore meeting the inclusion and exclusion criteria over a period of 24 months from January 2016 to December 2017.

After inclusion, detailed evaluation of the patient was done in the first phase of the initial 24-48 hours after admission. Baseline investigations included biochemical studies, radiological examinations of chest $\&$ abdomen and ultrasonography. Computer tomography where indicated was performed. The Baseline nutritional parameters recorded included anthropometric and biochemical measurements such as Body Mass Index, Mid Upper Arm Circumference, Triceps Skin Fold Thickness and Serum Albumin Levels.

In the Second Phase, the patients were randomized to receive either Nasogastric or Nasojejunal tube feeding, based on computer generated random numbers. The feeding tubes were placed in the stomach and jejunum under fluoroscopic guidance through the nasal route. Endoscopic assistance was taken for placement of nasojejunal tubes in patients in whom it was not successfully placed under fluoroscopic guidance. The diets in the two groups were similar in caloric, lipid and protein content. A semi-elemental enteral formula was used, given as low infusion at a rate of $1-2 \mathrm{ml} / \mathrm{min}$ through the enteral tube in both groups. Feeding was started with intake of $300 \mathrm{Kcal} /$ day to reach a target level of $2000 \mathrm{kcal} /$ day. Increase of the caloric intake from $300 \mathrm{Kcal} /$ day to $2000 \mathrm{Kcal} /$ day was over a 72 hour period and as tolerated. If a patient is unable to tolerate the prescribed rate of enteral feeding, the rate was reduced by $50 \%$ and gradually increased again when tolerated. Feeding through the tube was stopped at day 7; when the tube was removed and patients given oral feeding, depending on tolerance to oral feeding. Intravenous fluids such as crystalloids or colloids was added in both groups to fulfill the individual's needs of fluids and energy. Regular hospital diet was introduced initially starting with liquid followed by solid food.

Outcomes recorded were tolerance to feeding, feeding pain, hospital stay, changes in biochemical parameters, complications and their management and mortality. Local complications include pseudocyst, pancreatic necrosis, gastrointestinal bleed, and paralyticileus. Systemic complications include acute respiratory distress syndrome, pleural effusion, sepsis, acute renal failure, shock, disseminated intravascular coagulation and multiple organ dysfunction syndrome.

Exclusion criteria were a delay between onset of symptoms and presentation to hospital of over 4 weeks; a patient who is already on oral feeds at presentation; patients with an acute exacerbation of chronic pancreatitis and patient in shock at presentation.

Descriptive statistical analysis has been carried out in the present study. Significance is assessed at $5 \%$ level of significance. Student-t-test (two tailed, independent) has been used to find the significance of study parameters on continuous scale between two groups. On metric parameters Chi-square or Fisher Exact test has been used to find the significance of study parameters on categorical scale between two or more groups.

\section{Results}

During the 24 months study period, 30 patients of acute pancreatitis were fed by nasogastric route and 30 patients had nasojejunal feeding. The mean age group of the study subjects was 36.34 (range 22-64) years in nasogastric group and 38.73 (range 24-68) years in nasojejunal group. The gender distribution showed 30(100\%) males in nasogastric group; $28(93.33 \%)$ males and $2(6.67 \%)$ females in nasojejunal group. The etiology of pancreatitis include $21(70 \%)$ alchohol, 6(20\%) biliary and 3(10\%) others in nasogastric and 25(83.33\%) alchohol, 4(13.33\%) biliary and $1(3.33 \%)$ others in nasojejunal group. The Ranson score at 
presentation and at 48 hours after admission, APACHE score, CTSI and presence or absence of organ failure were used to assess the severity of acute pancreatitis. The severity was similar in both the nasogastric and nasojejunal groups (Table 1-2, Graph 1(i,ii)-4). The baseline Body mass index (BMI), Mid arm circumference (MAC) and triceps skin fold thickness(SFT) were similar in both nasogastric and nasojejunal groups. The total protein (TP) and serum albumin (Alb) as measured by biochemical tests were also similar in both groups.

Table 1. Comparison of Ranson's Score and Apache Score between Two Groups

\begin{tabular}{|c|c|c|c|c|c|}
\hline \multirow{2}{*}{$\begin{array}{c}\text { RANSON } \\
\text { SCORE }\end{array}$} & \multicolumn{4}{|c|}{\begin{tabular}{c|c|}
$\begin{array}{c}\text { NASOGASTRIC GROUP } \\
(n=30)\end{array}$ & $\begin{array}{c}\text { NASOJEJUNAL GROUP } \\
(\mathrm{n}=30)\end{array}$ \\
\end{tabular}} & \multirow[t]{2}{*}{ P VALUE } \\
\hline & NUMBER & $\%$ & NUMBER & $\%$ & \\
\hline \multicolumn{6}{|l|}{ At Presentation } \\
\hline$<3.0$ & 17 & 56.67 & 15 & 50 & \multirow{2}{*}{0.021} \\
\hline 3.0 & 13 & 43.33 & 15 & 50 & \\
\hline \multicolumn{6}{|l|}{ At 48 Hours } \\
\hline$<3.0$ & 18 & 60 & 19 & 63.33 & \multirow{2}{*}{0.042} \\
\hline 3.0 & 12 & 40 & 11 & 36.67 & \\
\hline \multirow[t]{2}{*}{ APACHE SCORE } & \multicolumn{2}{|c|}{$\begin{array}{l}\text { NASOGASTRIC } \\
\text { GROUP }(n=30)\end{array}$} & \multicolumn{2}{|c|}{$\begin{array}{l}\text { NASOJEJUNAL } \\
\text { GROUP }(n=30)\end{array}$} & \multirow[t]{2}{*}{ P VALUE } \\
\hline & NUMBER & $\%$ & NUMBER & $\%$ & \\
\hline$<8.0$ & 22 & 73.33 & 20 & 66.67 & \multirow{2}{*}{0.047} \\
\hline 8.0 & 8 & 26.67 & 10 & 33.33 & \\
\hline
\end{tabular}

Table 2. Comparison of CT Severity Index and Organ Failure between Two Groups

\begin{tabular}{|c|c|c|c|}
\hline $\begin{array}{l}\text { CT SEVERITY } \\
\text { INDEX }\end{array}$ & $\begin{array}{c}\text { NASOGASTRIC GROUP } \\
(\mathrm{n}=30)\end{array}$ & $\begin{array}{c}\text { NASOJEJUNAL GROUP } \\
(n=30)\end{array}$ & P VALUE \\
\hline$<6.0$ & $24(80 \%)$ & 22 (73.33\%) & \multirow{2}{*}{0.039} \\
\hline 6.0 & $6(20 \%)$ & $8(26.67 \%)$ & \\
\hline $\begin{array}{l}\text { ORGAN } \\
\text { FAILURE }\end{array}$ & $\begin{array}{l}\text { NASOGASTRIC } \\
\text { GROUP }(n=30)\end{array}$ & $\begin{array}{l}\text { NASOJEJUNAL } \\
\text { GROUP }(n=30)\end{array}$ & P VALUE \\
\hline YES & 23 (76.67\%) & $21(70 \%)$ & \multirow{2}{*}{0.05} \\
\hline $\mathrm{NO}$ & 7 (23.33\%) & $9(30 \%)$ & \\
\hline
\end{tabular}

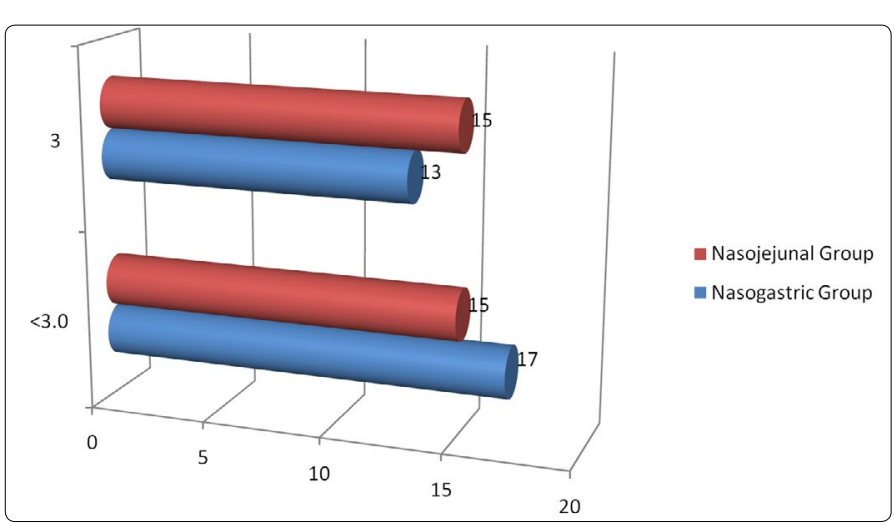

Graph 1(i). Comparison of Ranson's Score at Admission between Two Groups

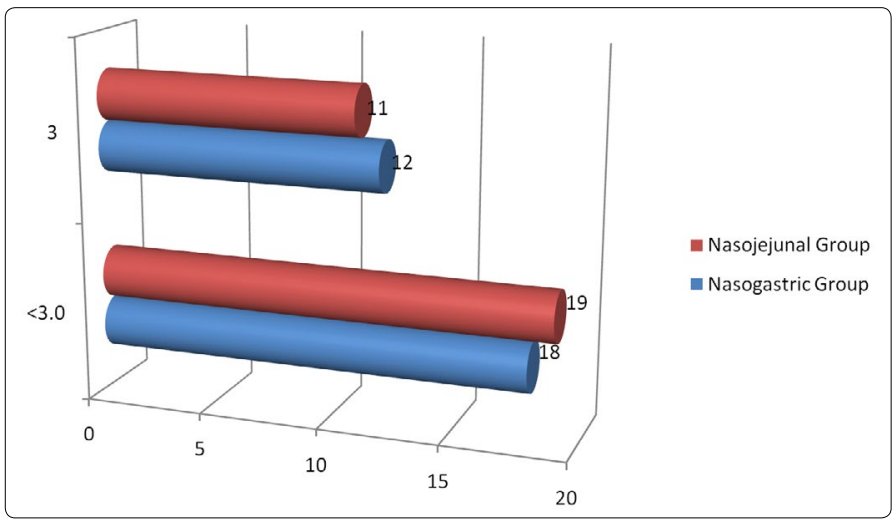

Graph 1 (ii). Comparison of Ranson's Score at 48 Hours between Two Groups

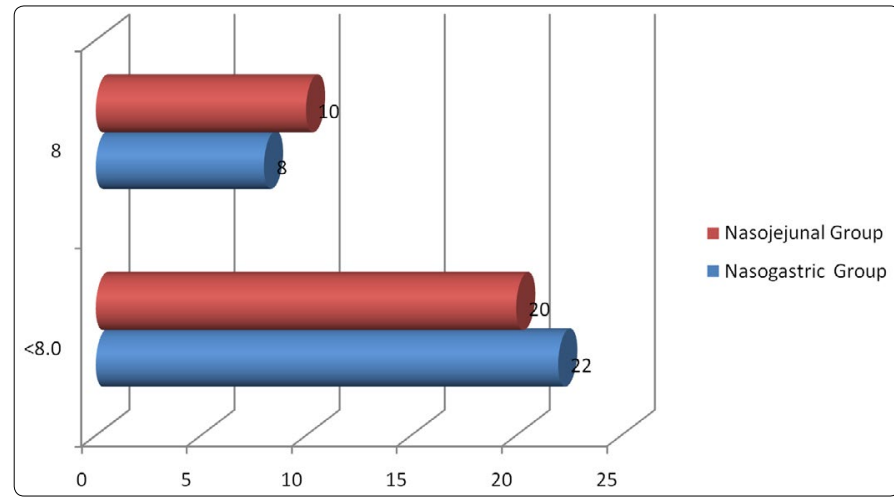

Graph 2. Comparison of APACHE Score between Two Groups

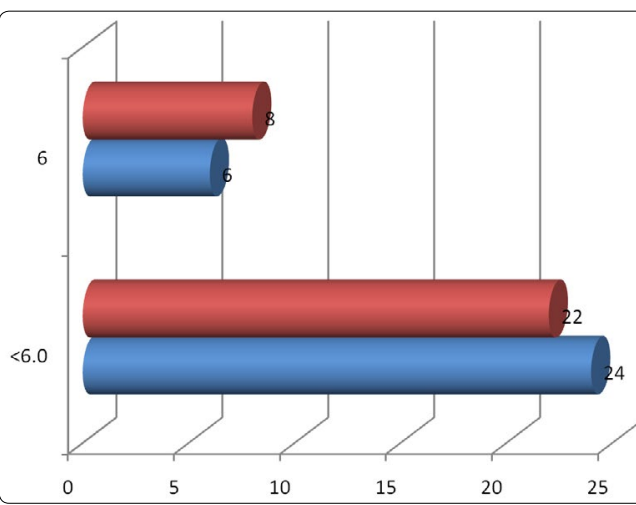

nasojejunal Group Nasogastric Group

Graph 3. Comparison of CT Severity Index between Two Groups

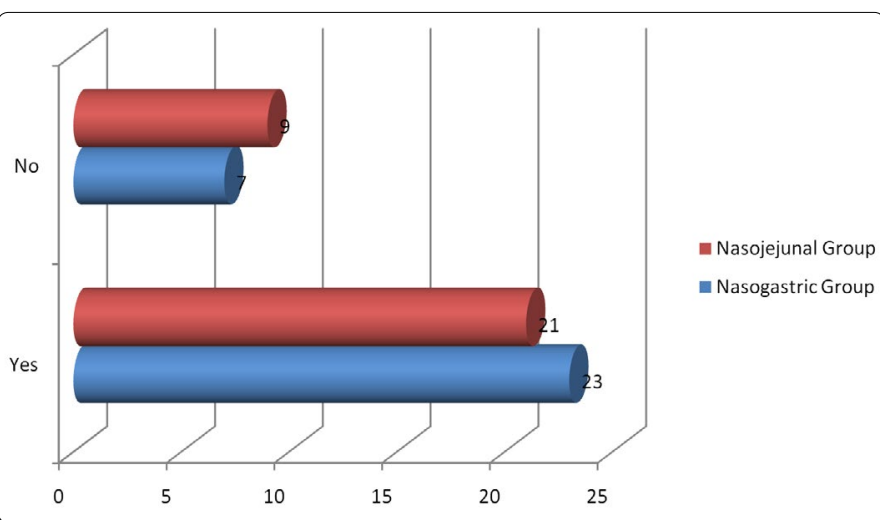

Graph 4. Comparison of Organ Failure between Two Groups

The Midarm circumference(MAC) and triceps skin fold thickness(SFT) and total protein(TP) and serum albumin(Alb) were measured in all patients at the end of one week, after receiving enteral nutrition. All parameters had decreased from the baseline in the nasogastric group as compared to nasojejunal group (Table 3).

Table 3. Assessment of Nutritional and Biochemical Parameters between two groups

\begin{tabular}{|c|c|c|c|}
\hline $\begin{array}{c}\text { NUTRITIONAL } \\
\text { PARAMETERS }\end{array}$ & $\begin{array}{c}\text { NASOGASTRIC GROUP } \\
(\mathrm{n}=30)\end{array}$ & $\begin{array}{c}\text { NASOJEJUNAL GROUP } \\
(\mathrm{n}=30)\end{array}$ & P VALUE \\
\hline MAC0 & $24.76 \pm 3.21$ & $25.44 \pm 3.12$ & 0.036 \\
\hline MAC2 & $22.38 \pm 3.06$ & $25.37 \pm 3.77$ & 0.022 \\
\hline SFT0 & $3.66 \pm 0.34$ & $3.86 \pm 0.39$ & 0.048 \\
\hline SFT2 & $3.05 \pm 0.37$ & $3.77 \pm 0.33$ & 0.05 \\
\hline $\begin{array}{c}\text { BIOCHEMICAL } \\
\text { PARAMETERS }\end{array}$ & $\begin{array}{c}\text { NASOGASTRIC GROUP } \\
(\mathrm{n}=30)\end{array}$ & $\begin{array}{c}\text { NASOJEJUNAL GROUP } \\
(\mathrm{n}=30)\end{array}$ & P VALUE \\
\hline TP0 & $6.31 \pm 0.31$ & $6.87 \pm 0.38$ & 0.022 \\
\hline TP2 & $5.02 \pm 0.67$ & $6.79 \pm 0.64$ & 0.041 \\
\hline ALB0 & $3.64 \pm 0.43$ & $3.76 \pm 0.47$ & 0.036 \\
\hline ALB2 & $2.22 \pm 0.55$ & $3.84 \pm 0.52$ & 0.001 \\
\hline
\end{tabular}


Length of hospital stay ranged from 5 days to 24 days (Mean-12.6 days). Nasogastric group ranged from 5 to 24 days (Mean-14.8 days). Nasojejunal group ranged from 5 to 16 days (Mean-9.4 days). Duration of hospital stay was statistically lesser in nasojejunal group ( $\mathrm{p}-0.05)$ as compared to nasogastric group.

$9(30 \%)$ patients in the nasogastric group and 3(10\%) patients in nasojejunal group required to stay in the ICU. $2(6.67 \%)$ patients in nasogastric group and $1(3.33 \%)$ in the nasojejunal group required surgical intervention in the form of necrosectomy. Total Mortality was 2(6.67\%) patients in nasogastric group and no patients died in nasojejunal group (Table 4, Graph 5).

Table 4. Comparison of Outcome among two groups

\begin{tabular}{|c|c|c|c|}
\hline OUTCOME & $\begin{array}{c}\text { NASOGASTRIC GROUP } \\
(\mathrm{n}=30) \mathrm{NASOJEJUNAL}\end{array}$ & $\begin{array}{c}\text { GROUP } \\
(\mathrm{n}=30)\end{array}$ & $\begin{array}{c}\mathrm{P} \\
\text { VALUE }\end{array}$ \\
\hline $\begin{array}{c}\text { Length Of Hospital Stay } \\
\text { (Days) }\end{array}$ & $14.8 \pm 3.68$ & $9.4 \pm 4.32$ & 0.05 \\
\hline Ventilator Support & $7(23.33 \%)$ & $2(6.67 \%)$ & 0.033 \\
\hline ICU & $9(15 \%)$ & $3(5 \%)$ & 0.04 \\
\hline Multiple Organ Failure & $6(10 \%)$ & $2(6.67 \%)$ & 0.001 \\
\hline Infected & $2(6.67 \%)$ & $1(3.33 \%)$ & 0.027 \\
\hline Acute Fluid Collection & $1(3.33 \%)$ & 0 & - \\
\hline
\end{tabular}

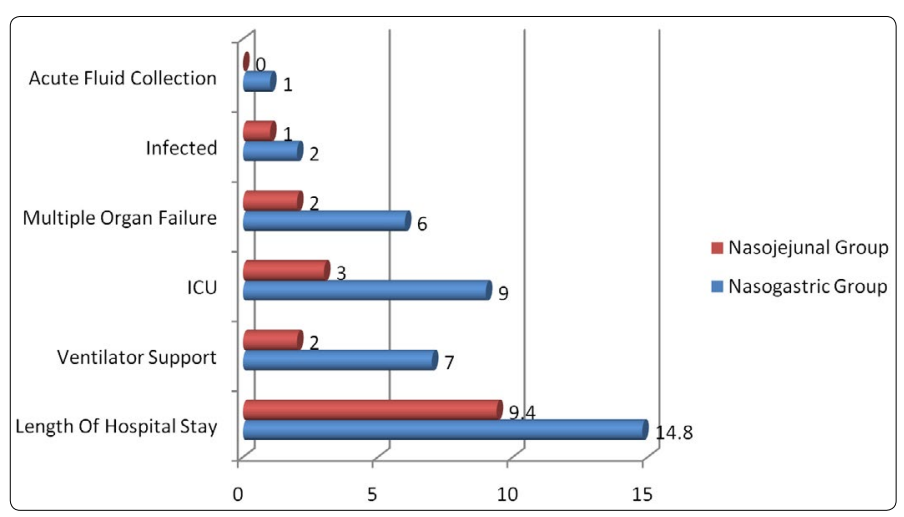

Graph 5. Comparison of Outcome among two groups

On comparing the tolerance and side effects pain or discomfort and diarrhoea during the first 48 hours of initiating feeds were commonly reported. The incidence of diarrhoea was $14(23.33 \%)$ and $5(8.33 \%)$ in nasogastric and nasojejunal groups respectively $(\mathrm{p}-0.036)$. However pain or discomfort was reported by $22(36.67 \%)$ of patients in nasogastric group as compared to $7(11.67 \%)$ in nasojejunal group. Only $1(3.33 \%)$ patient in nasogastric group had refeeding pain requiring discontinuation of enteral feeding.

\section{Discussion}

Bowel rest, Feeding and Nutritional support form an important aspect in the management of acute pancreatitis. Acute pancreatitis has been traditionally managed with initial fasting on purpose [5]. Until the mid 1990's, total parenteral nutrition had been recommended in the acute phase of pancreatitis to fulfill the nutritional requirements of the individual. Subsquently enteral nutrition was tried and presently enteral nutrition has replaced parenteral nutrition $[4,7,11]$. Enteral nutrition is effective, maintains the intestinal mucosal integrity and reduces infectious and other complications, such as multiple organ deficiency syndrome (MODS) $[15,16]$.
In acute pancreatitis, the nasojejunal route has been employed to deliver nutrients beyond the ligament of Treitz thereby giving the pancreas "rest". Delivery of nutrients proximal to the duodenojejunal flexure causes release of CCK and exaceberation of the inflammatory process [17]. Out of 60 study subjects, 30 subjects were nasogastric feeding group while 30 subjects were in nasojejunal group. The mean age group of the study subjects was 36.34 (range 22-64) years in nasogastric group and 38.73 (range 24-68) years in nasojejunal group. The mean age is lesser compared to the previous studies [18]. Most patients in this study were male with only two females, both in nasojejunal group compared to study done by Kumar et al. [19], showed all males in nasojejunal and two females in nasogastric group. The etiology was alcohol in about $76.67 \%$ and biliary in $16.67 \%$, which is similar to study done by Eatock et al. [20], and Kumar et al [19].

Severe acute pancreatitis was defined in the present study; in accordance with the Atlanta classification and the Ranson score at admission and at 48hours, APACHE-2 score at admission, CT severity index and presence or absence of Organ Failure were used to assess severity which were similar in these characteristics in both nasogastric and nasojejunal groups.

There was no significant difference in the nutritional parameters in the two groups at admission. But there was a decline in the nutritional parameters in nasogastric group, as shown by anthropometric measurements and biochemical levels at the end of the first week. However the study done by Petrov et al. [18], showed no statistically significant difference in both groups.

On comparison of outcomes between the nasogastric and nasojejunal groups; nasojejunal feeding group had lesser length of hospital stay, need for ventilator support, and less chances of multiple organ failure or infected necrosis as compared to nasogastric group ( $p$ 0.05). The ICU stay and formation of acute fluid collections were more in nasogastric group.

Previous studies reported overall length of stay in nasogastrically fed patients ranging from 7 to 82 days (Mean 9-24days). This was comparable to the patients receiving nasojejunal feeds. In the present study the mean length of stay was 14.8 days in the nasogastric group. However most studies reported a higher percentage of patients requiring ventilator support. Multiple organ failure in the present study was $9(15 \%)$ subjects which was similar to that of Kumar, et al of $18.8 \%$ [19].

$2(6.67 \%)$ patients in nasogastric group and $1(3.33 \%$ ) in the nasojejunal group required surgical intervention in the form of necrosectomy. The percentage of patients undergoing surgery was double in the nasogastric group. The need for surgery in the nasogastric group in the present study was similar to reports of Kumar et al. [19], and Eckerwall, et al [21]. Total Mortality was 2 patients in the nasogastric group and none in nasojejunal group. Overall Mortality reported was lesser than that of study done by Petrov et al [18].

Regarding side effects and tolerance to feeds, both nasogastric and nasojejunal groups tolerated feeds. On comparing the tolerance and side effects; pain or discomfort and 
diarrhoea during the first 48 hours of initiating feeds were commonly reported. The incidence of diarrhea was $14(23.33 \%)$ and $5(8.33 \%)$ in the nasogastric and nasojejunal groups respectively ( $p$ 0.036). Diarrhea was reported in 14 patients in the nasogastric group (23.33\%) which was higher compared with other studies but similar to that reported by Kumar et al (25\%) [19]. However pain or discomfort was reported in 22(36.67\%) patients in nasogastric group as compared to $7(11.67 \%)$ subjects in nasojejunal group (0.024). Only $1(3.33 \%)$ patient in nasogastric group had refeeding pain requiring discontinuation of enteral feeding. However; the study done by Eatock et al. [20], 2005 and Kumar et al. [19], 2006 showed one subject in nasojejunal group with refeeding pain $[19,20]$. Vomiting, distension, high ryles tube aspirate and tube removal were not a significant problem in the present study.

Nasojejunal group appeared to tolerate feeds better as compared to the nasogatric group. The target diet was reached within 3 days in the nasojejunal group in about $50 \%$ of the patients. Overall in about $20 \%$ of patients in either group the feed had to be stopped due to intolerance. However, there was no statistically significant difference between both groups in previous studies [18, 22].

\section{Conclusion}

The nasojejunal route of enteral nutrition appears to be simple, safe, well tolerated, easy to establish and effective route of enteral nutrition in predicting severe acute pancreatitis. However; there were few limitations in our study which include; small sample size, open label, hospital based and single center study. Further studies evaluating this, overcoming the above limitations is highly desired.

\section{Compliance with Ethical Standards}

Informed consents were taken from all participants, and the study protocol was approved by Institutional ethical committee approval board.

\section{Conflict of interest}

The authors confirm that there is no conflict of interest regarding this manuscript.

\section{References}

1. Imrie CW. Acute pancreatitis: Overview. Eur J Gastroenterol Hepatol. 1997; 9(2): 103-105.

2. McKay CJ, Buter A. Natural history of organ failure in acute pancreatitis. Pancreatology. 2003; 3: 111-114. doi: 10.1159/000070078

3. Bhatia M, Wong FL, Cao Y, Lau HY, Huang J, et al. Pathophysiology of Acute Pancreatitis. Pancreatology. 2005; 5(2-3): 132-144. doi: 10.1159/000085265

4. Heinrich $S$, Schäfer M, Rousson V, Clavien PA. Evidence-Based Treatment of Acute Pancreatitis. Ann Surg. 2006; 243(2): 154-168. doi: 10.1097/01. sla.0000197334.58374.70

5. Meier R, Beglinger C, Layer P, Gullo L, Keim V, et al. ESPEN guidelines on nutrition in acute pancreatitis. European Society of Parenteral and Enteral Nutrition. Clin Nutr. 2002; 21(2): 173-183. doi: 10.1054/clnu.2002.0543
6. Tesinsky P. Nutritional care of pancreatitis and its complications. Curr Opin Clin Nutr Metab Care. 1999; 2(5): 395-398.

7. Marik PE, Zaloga GP. Meta-analysis of parenteral nutrition versus enteral nutrition in patients with acute pancreatitis. BMJ. 2004; 328(7453): 1407. doi: $10.1136 / \mathrm{bmj} .38118 .593900 .55$

8. Al-Omran $\mathrm{M}, \mathrm{Groof} \mathrm{A}$, Wilke D. Enteral versus parenteral nutrition for acute pancreatitis. Cochrane Database Syst Rev. 2003. doi: 10.1002/14651858. CD002837

9. Hadfield RJ, Sinclair DG, Houldsworth PE, Evans TW. Effects of enteral and parenteral nutrition on gut mucosal permeability in the critically ill. $\mathrm{Am} \mathrm{J}$ Respir Crit Care Med. 1995; 152(5 Pt 1): 1545-1548. doi: 10.1164/ ajrccm.152.5.7582291

10. Vu MK, van der Veek PP, Frolich M, Souverijn JH, Biemond I, et al. Does jejunal feeding activate exocrine pancreatic secretion? Eur J Clin Invest. 1999; 29(12): 1053-1059.

11. Mitchell RM, Byrne MF, Baillie J. Pancreatitis. Lancet. 2003; 361(9367): 1447-1455.

12. Banks $P$, Freeman M. Practice guidelines in acute pancreatitis. Am J Gastroenterol.2006; 101(10):2379-400. doi: 10.1111/j.1572-0241.2006.00856.x

13. García de Casasola G, Cacho Acosta G, Gonzálvez-Gasch A, Barba Martín $R$, Herreros Valdepeñas $B$, et al. Nasogastric enteral nutrition in severe acute pancreatitis. Med Clin (Barc). 2008; 130(13): 492-493.

14. Jiang $K$, Chen $X Z$, Xia $Q$, Tang WF, Wang L. Early nasogastric enteral nutrition for severe acute pancreatitis: A systematic review. World J Gastroenterol. 2007; 13(39): 5253-60. doi: 10.3748/wjg.v13.i39.5253

15. Balthazar EJ, Robinson DL, Megibow AJ, Ranson JH. Acute pancreatitis: value of CT in establishing prognosis. Radiology. 1990. 174 (2): 331-336. doi: 10.1148/radiology.174.2.2296641

16. Talukdar R, Vege SS. Recent Developments in Acute Pancreatitis. Clin GastroenterolHepatol. 2009; 7(11 Suppl):S3-S9.doi:10.1016/j.cgh.2009.07.037

17. Eatock FC, Brombacher GD, Steven A, Imrie CW, McKay CJ, et al. Nasogastric feeding in severe acute pancreatitis may be practical and safe. Int J Pancreatol. 2000; 28(1): 23-29. doi: 10.1385/JGC:28:1:23

18. Petrov MS, Correia MI, Windsor JA. Nasogastric Tube Feeding in Predicted Severe Acute Pancreatitis. A Systematic Review of the Literature to Determine Safety and Tolerance. JOP. 2008; 9(4): 440-448.

19. Kumar A, Singh N, Prakash S, Saraya A, Joshi YK. Early enteral nutrition in severe acute pancreatitis: a prospective randomized controlled trial comparing nasojejunal and nasogastric routes. J Clin Gastroenterol. 2006; 40(5): 431-434.

20. Eatock FC, Chong P, Menezes N, Murray L, Imrie CW, et al. A randomized study of early nasogastric versus nasojejunal feeding in severe acute pancreatitis. Am J Gastroenterol. 2005; 100(2): 432-439. doi:10.1111/j.1572-0241.2005.40587.x

21. Eckerwall GE,Tingstedt $B B$, Bergenzaun PE, Andersson RG. Immediate oral feeding in patients with mild acute pancreatitis is safe and may accelerate recovery-a randomized clinical study. Clin Nutr. 2007; 26(6): 758-763. doi: 10.1016/j.clnu.2007.04.007

22. Johnson CD. UK Working Party on Acute Pancreatitis. UK guidelines for the management of acute pancreatitis. Gut. 2005; 54 (Suppl 3). doi: 10.1136/gut.2004.057026 